\title{
Association of XbaI GLUT1 Polymorphism with Susceptibility to Type 2 Diabetes Mellitus and Diabetic Nephropathy
}

\author{
Ragaa Abdelkader Ramadan ${ }^{*}$, Ahmad Mohamed Zaki ${ }^{1}$, Gehan Mahmoud Magour ${ }^{1}$, \\ Moyassar Ahmad Zaki', Sarah Ahmed Aglan', Marwa Ahmed Madkour², \\ Mohammed Mohammed Shamseya² \\ ${ }^{1}$ Chemical Pathology Department, Medical Research Institute, Alexandria University, Alexandria, Egypt \\ ${ }^{2}$ Clinical and Experimental Internal Medicine Department, Medical Research Institute, Alexandria University, \\ Alexandria, Egypt \\ Email: *ragaa.abdelkader@gmail.com
}

Received 17 September 2015; accepted 11 March 2016; published 14 March 2016

Copyright (C) 2016 by authors and Scientific Research Publishing Inc.

This work is licensed under the Creative Commons Attribution International License (CC BY). http://creativecommons.org/licenses/by/4.0/

(c) (i) Open Access

\section{Abstract}

Objectives: Diabetic nephropathy (DN) is one of the chronic microangiopathic complications of type 2 diabetes (T2DM) and has become the most frequent cause of end-stage renal disease. The Xbal polymorphism in the glucose transporter (GLUT1) has been suggested in the development of DN. We examined the association between XbaI polymorphism of GLUT1 and susceptibility to T2DM and development of DN. Methods: The study included 227 T2DM patients divided into 107 without DN (DM - DN) and 120 with DN (DM + DN), in addition to 100 apparently healthy controls. Genotyping was done by polymerase chain reaction restriction fragment length polymorphism (PCR-RFLP). Results: The GLUT1 XbaI T allele was associated with increased susceptibility to T2DM, when comparing the healthy controls to the whole diabetic group, odds ratio $(\mathrm{OR})=1.899$, 95\% confidence interval (CI) (1.149 - 3.136), $p=0.011$. This association was also significant between healthy controls and DM - DN OR $=1.997(1.079-3.699), p=0.026$ as well as between healthy controls and DM + DN OR = $1.818(1.016-3.253), p=0.042$. However there was no significant association of Xbal polymorphism with DN when comparing DM - DN to DM + DN OR = 0.910 $(0.474-1.747), p=0.777$. Conclusion: $\mathrm{XbaI} T$ allele is associated with increased susceptibility to T2DM, but not to development of DN. Further studies are needed to replicate such findings.

\section{Keywords}

Type 2 Diabetes Mellitus, Diabetic Nephropathy, Glucose Transporter 1, XbaI, Polymorphism

\footnotetext{
${ }^{*}$ Corresponding author.
}

How to cite this paper: Ramadan, R.A., Zaki, A.M., Magour, G.M., Zaki, M.A., Aglan, S.A., Madkour, M.A. and Shamseya, M.M. (2016) Association of Xbal GLUT1 Polymorphism with Susceptibility to Type 2 Diabetes Mellitus and Diabetic Nephropathy. American Journal of Molecular Biology, 6, 71-78. http://dx.doi.org/10.4236/ajmb.2016.62008 


\section{Introduction}

Diabetic nephropathy (DN) is a major long term chronic microangiopathic complications of diabetes mellitus, leading to end-stage renal disease [1]. It is defined by occurrence of albuminuria and/or proteinuria in a diabetic patient with no evidence of nondiabetic renal conditions [2]. It is characterized also by elevated arterial blood pressure, decline in glomerular filtration rate (GFR), and high risk of cardiovascular morbidity and mortality [3].

Glucose transporters (GLUTs) encompass a family of facilitative transporters classified into three classes [4]. GLUT1 is a member of class 1 and it is highly expressed in the glomeruli, mesangial, endothelial cells and podocytes [5]. GLUT1 gene (SLC2A1) (rs841853) is located on chromosome 1p34.2, and it contains 10 exons and 9 introns [6] [7]. It has a central role in the pathogenesis of DN because over expression of GLUT-1 in glomerular mesangial cells is expected to augment the basal glucose uptake [8], and activate cellular pathways involved in cellular growth and in accumulation of the extracellular matrix [9]. The expression and activity of mesangial GLUT1 in diabetic patients comprise great individual variability attributed mostly to genetic causes. From this perspective it becomes clear why only a certain group of diabetics are predisposed to the development of DN, and could also clarify the reason for the poor correlation between glycemic control and progression of nephropathy in a subset of diabetics [10]. Thus investigating the genetic susceptibility to the development of DN may shed light on the pathogenesis of renal involvement in diabetes mellitus. Several single nucleotide polymorphisms (SNP) of GLUT1 gene have been examined in relation to DN, of which is XbaI G > T, located within intron 2, which represents transversion of guanine $(\mathrm{G})$ to thymine (T) [9].

The conflicting data from worldwide studies done concerning XbaI G > T GLUT1 polymorphism in relation to DN [1] [9], and the fact that there were no studies in Egyptian population concerning this issue, made it noteworthy to study this polymorphism.

\section{Subjects and Methods}

\subsection{Selection of Study Participants}

We performed a case-control study of 227 diabetic patients attending the Teaching Hospital of Medical Research Institute, Alexandria University. All patients enrolled in this study were diagnosed as type 2 diabetes mellitus (DM2) according to the criteria based on the American Diabetes Association criteria (ADA) [11]. One hundred healthy subjects were also recruited from the same population. The study was explained to all participants and written informed consents were required. The experimental design was approved by the local ethical committee, and all participants gave their informed consent. All diabetics were receiving oral hypoglycemic agents.

Based on the guidelines of the ADA, albumin was measured in a spot urine sample collected as the first urine in the morning to identify nephropathy. Accordingly, diabetics were classified into non diabetic nephropathy patients $(\mathrm{DM}-\mathrm{DN})$ who were the normoalbuminuric with normal urinary albumin excretion $(<30 \mathrm{mg} / \mathrm{gm}$ urine creatinine), while diabetic nephropathy patients $(\mathrm{DM}+\mathrm{DN})$ were those with persistently increased urinary albumin excretion ( $\geq 30 \mathrm{mg} / \mathrm{gm}$ urine creatinine) based on the consensus of at least two consecutive overnight samples collected over a 3 - 6 month period [11].

General exclusion criteria included: DM2 with less than 10 years duration, type 1 diabetes, secondary diabetes, smoking, pregnancy, heart failure, previously diagnosed nondiabetic kidney disease. During urine sample collection; acute fever, diabetic ketoacidosis, significant bacteriuria or hematuria, or patients who performed excessive exercise within 24 hours were excluded and repeated after condition resolution. Ultrasound examination was done to exclude other non-diabetic organic kidney disease.

\subsection{Examination, Sampling and Biochemical Analysis}

All subjects had a standardized physical examination and provided detailed history regarding diagnosis and complications of DM as well as the type of anti-diabetic treatment received. Anthropometric measurements (weight and height) and calculation of body mass index were done to all participants.

Following an overnight 12 hour fast, eight milliliters of whole venous blood were withdrawn from each participant; whole EDTA blood was used for genomic DNA extraction and serum was used for routine clinical chemistry (concentrations of urea, creatinine, uric acid, triglycerides, cholesterol and its high density fraction). In addition, urinary albumin and creatinine were measured from morning urine sample. Glycated hemoglobin 
was determined using immunoturbidimetric assays. Analyses were conducted on the Olympus AU400 clinical chemistry analyzer (Beckman Coulter Inc., Brea CA, USA). Calculations of low density lipoprotein fraction using the Friedwald formula, estimated glomerular filtration rate (GFR) using the Cockroft and Gault formula, and urinary albumin to creatinine (UAC) ratio were done.

\subsection{Genotyping of Xbal Polymorphism of the GLUT1 Gene}

Genomic DNA was extracted using a commercially available kit (Qiagen). The concentration and purity of extracted DNA were determined by NanoDropTM 1000 spectrophotometer (Thermo Fisher Scientific) at 260 and $280 \mathrm{~nm}$. The polymerase chain reactions were carried out in a Veriti thermal cycler (Applied Biosystems) according to the method described by Grabellus et al. (2010) [12]. The PCR reaction was carried out in a total volume of $25 \mu \mathrm{L}$, containing $10 \mu \mathrm{L}$ of genomic DNA, $12.5 \mathrm{ml}$ of DreamTaq ${ }^{\mathrm{TM}}$ Green PCR Master Mix, 20 pmol/l of each primer, $2.1 \mu \mathrm{L}$ of nuclease free water. The primer sequences were; forward 5'-TGC AAC CCA TGA GCT AAC AA-3' and reverse 5'-GAA CCC AGC ACT CTG TAG CC-3' [12]. PCR program was initial denaturation $94^{\circ} \mathrm{C}$ for 3 min followed by annealing and extension for 30 cycles of $45 \mathrm{~s}$ at $94^{\circ} \mathrm{C}$ and $45 \mathrm{~s}$ at $56^{\circ} \mathrm{C}$ and $72^{\circ} \mathrm{C}$ for $45 \mathrm{~s}$, with a final extension step of $7 \mathrm{~min}$ at $72^{\circ} \mathrm{C}$. The PCR products were digested with XbaI restriction enzyme (Roche Molecular Dagnostics, Germany) and incubated in $37^{\circ} \mathrm{C}$ for 1 hour. In the mutant form, guanine $(\mathrm{G})$ has been transverse to thymine $(\mathrm{T})$ and abolished the recognition site. Hence, $\mathrm{T}$ allele which did not contain the XbaI restriction enzyme site remained undigested as 305 bp fragments, whereas $\mathrm{G}$ allele yields 232and 73-bp fragments [12]. The resultant PCR products were visualized by electrophoresis on 3\% agarose gel stained with ethidium bromide for visualization under UV light (Figure 1). In 5\% of the samples genotyping was performed in duplicate and was fully concordant.

\subsection{Statistical Analysis}

Continuous results that satisfied a normal distribution were expressed as mean \pm standard deviation. The Student's t-test, chi-square test, and Fisher exact test were used to assess the general characteristics between groups. The Hardy-Weinberg equilibrium was performed using chi square test by comparing the observed to the expected genotype frequencies. The association between variant alleles and their susceptibility to disease was assessed, and odds ratios (ORs) with 95\% confidence intervals and chi-square tests were calculated. All statistical tests were two-tailed and p-values less than 0.05 were considered statistically significant. Statistical Program for Social Sciences (SPSS) version 20 was used for analysis of data.

\section{Results}

This case-control study included 100 healthy adults (56\% males) with age 47 (34 - 66) years and 227 unrelated type 2 diabetics, stratified according to occurrence of diabetic nephropathy into; 107 diabetics without diabetic nephropathy $(\mathrm{DM}-\mathrm{DN})$ and 120 diabetics with diabetic nephropathy $(\mathrm{DM}+\mathrm{DN})$.

Although duration of diabetes was higher in $(\mathrm{DM}+\mathrm{DN})$ when compared to $(\mathrm{DM}-\mathrm{DN})$ but this did not reach the level of statistical significance $(p=0.348)$. HbA1c was significantly higher in $(\mathrm{DM}+\mathrm{DN})$ when compared to $(\mathrm{DM}-\mathrm{DN})$. As expected, the studied renal parameters were higher in $(\mathrm{DM}+\mathrm{DN})$ when compared to $(\mathrm{DM}-$ DN). The lipid profile showed no significant difference among groups, except for higher triglyceride level in $(\mathrm{DM}+\mathrm{DN})$ when compared to $(\mathrm{DM}-\mathrm{DN})($ Table 1$)$.

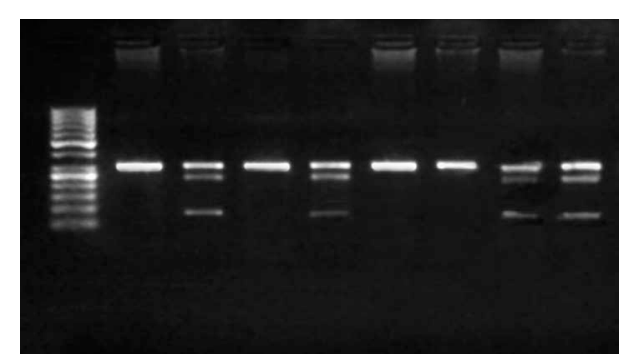

Figure 1. Agarose gel electrophoresis showing patterns of XbaI polymorphism of the GLUT1 gene. Lane 1: 50 bp ladder; lanes 2, 4, 6, 7 denote TT genotype; lanes 3, 5, 8, 9 denote GT genotype. 
Table 1. Demographic and biochemical parameters of the studied sample.

\begin{tabular}{|c|c|c|c|c|}
\hline Variable & Whole diabetics & $\mathrm{DM}-\mathrm{DN}$ & $\mathrm{DM}+\mathrm{DN}$ & $p$ value \\
\hline Number (\%) & $227(100)$ & $107(47.1)$ & 120 (52.9) & - \\
\hline Gender (\% men) & $110(48.2)$ & 49 (45.8) & $61(50.8)$ & 0.448 \\
\hline Age (years) & $\begin{array}{c}51.0 \\
(32.0-66.0)\end{array}$ & $\begin{array}{c}52.0 \\
(38.0-65.0)\end{array}$ & $\begin{array}{c}51.0 \\
(32.0-66.0)\end{array}$ & 0.850 \\
\hline Duration of diabetes (years) & $\begin{array}{c}12.0 \\
(10.0-22.0)\end{array}$ & $\begin{array}{c}11.0 \\
(10.0-20.0)\end{array}$ & $\begin{array}{c}14.0 \\
(11.0-22.0)\end{array}$ & 0.348 \\
\hline $\mathrm{BMI}\left(\mathrm{Kg} / \mathrm{m}^{2}\right)$ & $\begin{array}{c}31.2 \\
(21.5-39.5)\end{array}$ & $\begin{array}{c}32.0 \\
(21.5-39.5)\end{array}$ & $\begin{array}{c}31.0 \\
(23.4-39.1)\end{array}$ & 0.951 \\
\hline $\mathrm{HbA}_{1 \mathrm{C}}(\%)$ & $8.65 \pm 1.83$ & $8.19 \pm 1.53$ & $9.07 \pm 0.97$ & $<0.001^{*}$ \\
\hline UAC (mg/gm) & $\begin{array}{c}46.0 \\
(4.6-1749.0)\end{array}$ & $\begin{array}{c}14.5 \\
(4.6-29.0)\end{array}$ & $\begin{array}{c}172.7 \\
(43.3-1749.2)\end{array}$ & $<0.001^{*}$ \\
\hline Serum creatinine (mg/dl) & $1.0(0.6-5.7)$ & $\begin{array}{c}0.9 \\
(0.7-1.3)\end{array}$ & $\begin{array}{c}1.1 \\
(0.6-5.7)\end{array}$ & $<0.001^{*}$ \\
\hline eGFR (ml/min) & $\begin{array}{c}85.7 \\
(14.6-155.0)\end{array}$ & $\begin{array}{c}91.5 \\
(62.5-155.0)\end{array}$ & $\begin{array}{c}72.0 \\
(14.6-132.7)\end{array}$ & $<0.001^{*}$ \\
\hline Uric acid (mg/dl) & $\begin{array}{c}4.7 \\
(3.2-10.2)\end{array}$ & $\begin{array}{c}4.5 \\
(3.2-6.7)\end{array}$ & $\begin{array}{c}5.6 \\
(3.7-10.2)\end{array}$ & $<0.001^{*}$ \\
\hline Total cholesterol (mg/dl) & $\begin{array}{c}219.0 \\
(130.0-286.0)\end{array}$ & $\begin{array}{c}219.0 \\
(168.0-269.0)\end{array}$ & $\begin{array}{c}221.5 \\
(130.0-286.0)\end{array}$ & 0.661 \\
\hline Triglycerides (mg/dl) & $\begin{array}{c}168.0 \\
(68.0-272.0)\end{array}$ & $\begin{array}{c}158.0 \\
(78.0-266.0)\end{array}$ & $\begin{array}{c}171.0 \\
(68.0-272.0)\end{array}$ & $0.029^{*}$ \\
\hline HDL-C (mg/dl) & $\begin{array}{c}43.0 \\
(25.0-78.0)\end{array}$ & $\begin{array}{c}45.0 \\
(26.0-78.0)\end{array}$ & $\begin{array}{c}43.0 \\
(25.0-67.0)\end{array}$ & 0.275 \\
\hline LDL-C (mg/dl) & $143.7 \pm 29.2$ & $143.3 \pm 27.1$ & $144.1 \pm 31.1$ & 0.830 \\
\hline
\end{tabular}

DM - DN: diabetic patients without diabetic retinopathy, DM + DN: diabetic patients with diabetic retinopathy, BMI: body mass index, HbA1c: glycated hemoglobin, UAC: urinary albumin creatinine ratio, eGFR: estimated glomerular filtration rate, HDL-C, LDL-C: high and low density lipoprotein cholesterol.

All genotype groups obeyed the Hardy-Weinberg equilibrium; $p=0.07$ in healthy control and $p=0.145$ in whole diabetics group. We did not find any homozygous (GG) genotype in the studied population neither in healthy controls, nor in diabetics. TT genotype was significantly more frequent in whole diabetics (82.38\%), $\mathrm{DM}-\mathrm{DN}(83.2 \%)$ and DM + DN (81.7\%) than in the healthy controls (69\%). The difference in the genotype frequencies was also reflected in the allelic frequencies. XbaI polymorphism $\mathrm{T}$ allele was associated with increased susceptibility to diabetes, when comparing healthy controls to that of the whole diabetic group, odds ratio $(\mathrm{OR})=1.899,95 \%$ confidence interval $(\mathrm{CI})(1.149-3.136), p=0.011$. This significant difference was also present between healthy controls and DM $-\mathrm{DN}$, OR $=1.997(1.079-3.699), p=0.026$ as well as between healthy controls and DM + DN OR $=1.818(1.016-3.253), p=0.042$. However, there was no association of Xbal polymorphism between DM $-\mathrm{DN}$ and $\mathrm{DM}+\mathrm{DN}, \mathrm{OR}=0.910(0.474-1.747), p=0.777$ (Table 2). We examined the studied parameters according to genotypes of XbaI polymorphism, but no significant difference was noted (Table 3).

\section{Discussion}

Diabetic nephropathy (DN) occurs in $20 \%-40 \%$ of diabetics and is the single leading cause of end stage renal disease. It imposes a high social and economic burden. Persistent albuminuria in the range of $30-299 \mathrm{mg} / 24 \mathrm{~h}$ has been shown to be an early stage of DN in type 1 diabetes and a marker for development of nephropathy in type 2 diabetes. In addition, DN is a well-established marker of increased cardiovascular risk [11]. Apparently, hyperglycemia can no longer be the sole etiological factor in development of DN. This is supported by familial clustering of renal complications and ethnic variations. Therefore, genetic causes are considered a major contributor of occurrence and progression of DN [10]. The GLUT1 is a plausible candidate gene in diabetes research, 
Table 2. Genotype and allele frequency of XbaI polymorphism of GLUT1 in the studied population.

\begin{tabular}{|c|c|c|c|c|c|c|}
\hline Genotype/allele & $\begin{array}{l}\text { Healthy } \\
(\mathrm{n}=100)\end{array}$ & $\begin{array}{l}\text { Whole diabetics } \\
\quad(\mathrm{n}=227)\end{array}$ & $\begin{array}{c}\mathrm{DM}-\mathrm{DN} \\
(\mathrm{n}=107)\end{array}$ & $\begin{array}{l}\mathrm{DM}+\mathrm{DN} \\
(\mathrm{n}=120)\end{array}$ & $p$ value & OR, 95\% CI \\
\hline GG & 0 & $0(0)$ & $0(0)$ & $0(0)$ & & \\
\hline GT & 31 & $40(17.62)$ & $18(16.8)$ & $22(18.3)$ & $0.007^{*}$ & $2.100(1.219-3.610)$ \\
\hline \multirow[t]{3}{*}{$\mathrm{TT}$} & 69 & $187(82.38)$ & 89 (83.2) & 98 (81.7) & $0.017^{\#}$ & $2.221(1.148-4.300)$ \\
\hline & & & & & $0.029^{\approx}$ & $2.000(1.069$ - 3.747) \\
\hline & & & & & $0.766^{\pi}$ & $0.901(0.454-1.789)$ \\
\hline \multicolumn{7}{|l|}{ Allele } \\
\hline G & 31 (15.5) & $40(8.8)$ & $18(8.4)$ & $22(9.2)$ & & \\
\hline \multirow[t]{4}{*}{$\mathrm{T}$} & $169(84.5)$ & $414(91.2)$ & 196 (91.6) & 218 (90.8) & $0.011^{*}$ & $1.899(1.149$ - 3.136$)$ \\
\hline & & & & & $0.026^{\#}$ & $1.997(1.079$ - 3.699) \\
\hline & & & & & $0.042^{\approx}$ & $1.818(1.016-3.253)$ \\
\hline & & & & & $0.777^{\Uparrow}$ & $0.910(0.474-1.747)$ \\
\hline
\end{tabular}

DM - DN: diabetic patients without diabetic retinopathy, DM + DN: diabetic patients with diabetic retinopathy. OR: odds ratio, CI: confidence interval. ${ }^{*}$ Comparison between healthy control and whole diabetics; ${ }^{\#}$ Comparison between healthy control and DM - DN; ${ }^{\sim}$ Comparison between healthy control and DM + DN; "Comparison between DM - DN and DM + DN.

Table 3. Demographic data and biochemical parameters according to genotypes of XbaI polymorphism in type 2 diabetics.

\begin{tabular}{cccc}
\hline Item & TT & GT & $p$ value \\
\hline Number (\%) & $187(82.4 \%)$ & $40(17.6 \%)$ & 0.362 \\
Gender (\% men) & $88(47.1 \%)$ & $22(55.0 \%)$ & 0.550 \\
Age (years) & $51(38-66)$ & $52(32-66)$ & 0.390 \\
Duration of diabetes (years) & $12.0(10.0-22.0)$ & $14.0(10.0-22.0)$ & 0.716 \\
BMI & $31.0(21.50-39.10)$ & $32.0(22.0-39.50)$ & 0.330 \\
Fasting plasma glucose (mg/dl) & $169(78-346)$ & $167(79-327)$ & 0.652 \\
HbA 1 (\%) & $8.63 \pm 1.81$ & $8.77 \pm 1.93$ & 0.622 \\
UAC ratio (mg/gm) & $46.0(4.6-1749.2)$ & $49.2(5.3-954.5)$ & 0.723 \\
Serum creatinine (mg/dl) & $1.0(0.6-5.7)$ & $1.0(0.6-5.7)$ & 0.716 \\
eGFR (ml/min) & $85.7(14.6-155.0)$ & $89.5(14.6-136.5)$ & 0.358 \\
Uric acid (mg/dl) & $4.7(3.2-10.2)$ & $4.7(4.1-8.9)$ & 0.466 \\
Total cholesterol (mg/dl) & $219(134-286)$ & $224(130-265)$ & 0.350 \\
Triglycerides (mg/dl) & $168(78-272)$ & $188(68-266)$ & 0.955 \\
HDL-C (mg/dl) & $43(25-67)$ & $43(26-78)$ & 0.977 \\
LDL-C (mg/dl) & $143.7 \pm 28.9$ & $143.9 \pm 31.2$ &
\end{tabular}

BMI: body mass index, HbA1c: glycated hemoglobin, UAC: urinary albumin creatinine ratio, eGFR: estimated glomerular filtration rate, HDL-C, LDL-C: high and low density lipoprotein cholesterol.

because GLUT1 is the main facilitative glucose transporter. In this case control study, we found that the T allele of XbaI GLUT1 gene polymorphism was associated with increased risk of susceptibility to T2DM, but not to development of DN.

The genotypes reported in our study obeyed the Hardy-Weinberg equilibrium. The $\mathrm{G}$ and $\mathrm{T}$ allele frequencies in the healthy control group were $15.5 \%$ and $84.5 \%$ respectively. We did not find GG genotype in any of the 
studied subgroups. This was quite different from other studies [9] [10] [13] [14]. Variation in XbaI polymorphism genotype frequencies in healthy population is noted among different ethnicities for example the frequency of $\mathrm{T}$ allele in British Caucosid [15] was more than twice that reported in Chinese (51\% in former and $21 \%$ in latter) [10], taken into consideration that both studies did not deviate from Hardy-Weinberg equilibrium.

In this case-control study, the GLUT1 XbaI T allele was associated with increased susceptibility to T2DM, when comparing the healthy controls to the whole diabetic group, odds ratio $(\mathrm{OR})=1.899,95 \%$ confidence interval (CI) (1.149 - 3.136), $p=0.011$. This association was also significant between healthy controls and DM DN OR $=1.997$ (1.079 - 3.699), $p=0.026$ as well as between healthy controls and DM + DN OR = $1.818(1.016$ - 3.253), $p=0.042$. The XbaI polymorphism has been previously studied in association to risk of DM, but results were inconsistent. Significant association was reported in Japanese [16] [17] and Italians [18], but other studies could not confirm such association [19] [20]. The XbaI polymorphism has an intronic nature and it can hardly cause changes in the protein sequence. Thus, it can be assumed that the XbaI polymorphism is in linkage disequilibrium with another locus which does have significant functional implications at the protein level [9].

In the current study, GLUT1 XbaI polymorphism was not associated with DN. Over the past years, conflicting results were reported from different studies concerning the association of GLUT1 Xba polymorphism and DN in type 2 diabetic patients [9] [10] [13] [14] as well as in type 1 diabetic patients [15] [21] [22]. The non significant association of the XbaI polymorphism of GLUT1 gene with DN found in the present study was in agreement with studies done in T2DM in Caucasian Mediterranean population [23] and in Tunisians [14]. Also in type 1 DM no significant association of the XbaI polymorphism with DN was reported in Danish population [21]. On the other hand, a study by Liu et al. indicated that type 2 diabetic patients with XbaI (T) allele of the GLUT1 gene may be prone to DN in Chinese subjects [10]. A finding that was supported by later studies in different populations including; a study on Mediterranean Caucasian population which showed an association with T2DM and possibly a severe form of it that leads to the development of DN. It further showed a statistically significant association between the XbaI (T) carriage and the presence of arterial hypertension in type 2 DM patients. However when they considered hypertension as a confounding factor, the association between GLUT1 XbaI G > T polymorphism and DN was no longer significant [9]. Also, another study on European Americans found that those having homozygous XbaI T allele were associated with DN, and suggested that enhancer 2 (Enh2) SNP, and not XbaI, is the causative polymorphism associated with diabetic albuminuria [24]. There is great heterogeneity in genetic studies; ethnicity of the studied population, demographics including different age and gender distribution. And above all, non uniformity in selection criteria of cases, for example definition of DN can range from microalbuminuria in spot urine sample, proteinuria in $24 \mathrm{hr}$ urine and/or impaired renal function, thus making comparability of results quite difficult [1].

It is worth mentioning that a meta-analysis including several studies upon different populations concluded that XbaI polymorphhism in GLUT1 gene may represent a genetic susceptibility to DN. However, it did not support the association between XbaI and the severity of DN [25]. Nevertheless, (Grzeszczak et al., 2001) study in Caucasians from Poland was not in agreement with all the aforementioned studies and it even suggested that the XbaI (T) allele protects against the development of DN, given that the frequency of the XbaI (GG) genotype increased with each stage of DN. They found that patients with microalbuminuria had a higher frequency of XbaI (GG) genotype than those with normoalbuminuria and in the group with proteinuria/chronic renal failure the frequency of XbaI, (GG) genotype was the highest [13].

\section{Conclusion}

In conclusion, the association between GLUT1 XbaI polymorphism and DN is still debatable up to date due to the contradictory reports from different populations. In the same context, the present study was only able to demonstrate an association between this polymorphism and susceptibility to T2DM but not DN. Further studies on larger sample size are needed to replicate such findings.

\section{Disclosure}

Authors have not conflict of interest to disclose.

\section{References}

[1] Zintzaras, E. and Stefanidis, I. (2005) Association between the GLUT1 Gene Polymorphism and the Risk of Diabetic 
Nephropathy: A Meta-Analysis. Journal of Human Genetics, 50, 84-91. http://dx.doi.org/10.1007/s10038-004-0224-6

[2] Delaney, M.P., Price, C.P. and Lamb, E.J. (2012) Kidney Disease. In: Burtis, C.A., Ashwood, E.R. and Bruns, D.E., Eds., Tietz Textbook of Clinical Chemistry and Molecular Diagnostics, 5th Edition, Elsevier Saunders Company, St. Louis, 1523-1608. http://dx.doi.org/10.1016/b978-1-4160-6164-9.00048-2

[3] Jawa, A., Kcomt, J. and Fonseca, V.A. (2004) Diabetic Nephropathy and Retinopathy. Medical Clinics of North America, 88, 1001-1036. http://dx.doi.org/10.1016/j.mcna.2004.04.012

[4] Thorens, B. and Mueckler, M. (2010) Glucose Transporters in the 21st Century. The American Journal of PhysiologyEndocrinology and Metabolism, 298, 141-145. http://dx.doi.org/10.1152/ajpendo.00712.2009

[5] Heilig, C.W., Brosius, F.C. and Henry, D.N. (1997) Glucose Transporters of the Glomerulus and the Implications for Diabetic Nephropathy. Kidney International, 52, 91-99.

[6] Brockmann, K., Wang, D., Korenke, C.G., Von Moers, A., Ho, Y.Y., Pascual, J.M., et al. (2001) Autosomal Dominant Glut-1 Deficiency Syndrome and Familial Epilepsy. Annals of Neurology, 50, 476-485. http://dx.doi.org/10.1002/ana.1222

[7] Wang, D., Pascual, J.M., Yang, H., Engelstad, K., Jhung, S., Sun, R.P., et al. (2005) Glut-1 Deficiency Syndrome: Clinical, Genetic, and Therapeutic Aspects. Annals of Neurology, 57, 111-118. http://dx.doi.org/10.1002/ana.20331

[8] Li, Y., Liu, Z., Liu, D., Zhang, J., Chen, Z. and Li, L. (2001) Identification and Function of Glucose Transporter 1 in Human Mesangial Cells. Chinese Medical Journal (English), 114, 824-828.

[9] Stefanidis, I., Kytoudis, K., Papathanasiou, A.A., Zaragotas, D., Melistas, L. and Kitsios, G.D. (2009) XbaI GLUT1 Gene Polymorphism and the Risk of Type 2 Diabetes with Nephropathy. Disease Markers, 27, 29-35. http://dx.doi.org/10.1155/2009/797601

[10] Liu, Z.H., Guan, T.J., Chen, Z.H. and Li, L.S. (1999) Glucose Transporter (GLUT 1) Allele (XbaI-)Associated with Nephropathy in Non-Insulin-Dependent Diabetes Mellitus. Kidney International, 55, 1843-1848. http://dx.doi.org/10.1046/j.1523-1755.1999.00449.x

[11] American Diabetes Association (2011) Standards of Medical Care in Diabetes. Diabetes Care, 34, 11-61. http://dx.doi.org/10.2337/dc11-S011

[12] Grabellus, F., Sheu, S.Y., Bachmann, H.S., Lehmann, N., Otterbach, F., Heusner, T.A., et al. (2010) The XbaI G>T Polymorphism of the Glucose Transporter 1 Gene Modulates 18F-FDG Uptake and Tumor Aggressiveness in Breast Cancer. Journal of Nuclear Medicine, 51, 1191-1197. http://dx.doi.org/10.2967/jnumed.110.075721

[13] Grzeszczak, W., Moczulski, D.K., Zychma, M., Zukowska-Szczechowska, E., Trautsolt, W. and Szydlowska, I. (2001) Role of GLUT1 Gene in Susceptibility to Diabetic Nephropathy in Type 2 Diabetes. Kidney International, 59, 631-636. http://dx.doi.org/10.1046/j.1523-1755.2001.059002631.x

[14] Makni, K., Jarraya, F., Rebai, M., Mnif, F., Boudawara, M., Hamza, N., et al. (2008) Risk Genotypes and Haplotypes of the GLUT1 Gene for Type 2 Diabetic Nephropathy in the Tunisian Population. Annals of Human Biology, 35, 490498. http://dx.doi.org/10.1080/03014460802247142

[15] Hodgkinson, A.D., Millward, B.A. and Demaine, A.G. (2001) Polymorphisms of the Glucose Transporter (GLUT1) Gene Are Associated with Diabetic Nephropathy. Kidney International, 59, 985-989. http://dx.doi.org/10.1046/j.1523-1755.2001.059003985.x

[16] Li, S.R., Baroni, M.G., Oelbaum, R.S., Stock, J. and Galton, D.J. (1988) Association of Genetic Variant of the Glucose Transporter with Non-Insulin-Dependent Diabetes Mellitus. The Lancet, 2, 368-370. http://dx.doi.org/10.1016/S0140-6736(88)92836-X

[17] Tao, T., Tanizawa, Y., Matsutani, A., Matsubara, A., Kaneko, T. and Kaku, K. (1995) HepG2/Erythrocyte Glucose Transporter (GLUT1) Gene in NIDDM: A Population Association Study and Molecular Scanning in Japanese Subjects. Diabetologia, 38, 942-947. http://dx.doi.org/10.1007/BF00400583

[18] Baroni, M.G., Alcolado, J.C., Gragnoli, C., Franciosi, A.M., Cavallo, M.G., Fiore, V., et al. (1994) Affected Sib-Pair Analysis of the GLUT1 Glucose Transporter Gene Locus in Non Insulin-Dependent Diabetes Mellitus (NIDDM): Evidence for No Linkage. Human Genetics, 995, 675-680. http://dx.doi.org/10.1007/bf00201569

[19] Alcado, J.C. and Baroni, M.G. (1992) Restriction Fragment Length Polymorphisms at the GLUT4 and GLUT1 Gene Loci in Type 2 Diabetes. Diabetic Medicine, 9, 58-60. http://dx.doi.org/10.1111/j.1464-5491.1992.tb01715.x

[20] Elbein, S.C., Hoffman, M.D., Matsutani, A. and Permutt, M.A. (1992) Linkage Analysis of GLUT1 (HepG2) and GLUT2 (Liver/Islet) Genes in Familial NIDDM. Diabetes, 41, 1660-1667. http://dx.doi.org/10.2337/diab.41.12.1660

[21] Tarnow, L., Grarup, N., Hansen, T., Parving, H.H. and Pedersen, O. (2001) Diabetic Microvascular Complications Are Not Associated with Two Polymorphisms in the GLUT-1 and PC-1 Genes Regulating Glucose Metabolism in Caucasian Type 1 Diabetic Patients. Nephrology Dialysis Transplantation, 16, 1653-1656. http://dx.doi.org/10.1093/ndt/16.8.1653 
[22] Ng, D.P., Canani, L., Araki, S., Smiles, A., Moczulski, D., Warram, J.H., et al. (2002) Minor Effect of GLUT1 Polymorphisms on Susceptibility to Diabetic Nephropathy in Type 1 Diabetes. Diabetes, 51, 2264-2269. http://dx.doi.org/10.2337/diabetes.51.7.2264

[23] Gutierrez, C., Vendrell, J., Pastor, R., Broch, M., Aguilar, C., Lior, C., et al. (1998) GLUT1 Gene Polymorphism in Non-Insulin-Dependent Diabetes Mellitus: Genetic Susceptibility Relationship with Cardiovascular Risk Factors and Microangiopathic Complications in a Mediterranean Population. Diabetes Research and Clinical Practice, 41, 113-120. http://dx.doi.org/10.1016/S0168-8227(98)00050-3

[24] Hsu, C.C., Kao, W.L., Steffes, M.W., Gambir, T., Brancati, F.L., Heilig, C.W., et al. (2011) Genetic Variation of Glucose Transporter-1 (GLUT1) and Albuminuria in 10,278 European Americans and African Americans: A Case-Control Study in the Atherosclerosis Risk in Communities (ARIC) Study. BMC Medical Genetics, 12, 16. http://dx.doi.org/10.1186/1471-2350-12-16

[25] Cui, W., Du, B., Zhou, W., Jia, Y., Sun, G. and Sun, J. (2012) Relationship between Five GLUT1 Gene Single Nucleotide Polymorphisms and Diabetic Nephropathy: A Systematic Review and Meta-Analysis. Molecular Biology Reports, 39, 8551-8558. http://dx.doi.org/10.1007/s11033-012-1711-z 